\title{
2015: O ANO DE TRISTE MEMÓRIA PARA O DIREITO FINANCEIRO QUE NÃO QUER TERMINAR
}

Coluna publicada em 15.12.2015:<http://www.conjur.com.br/ 2015-dez-15/contas-vista-2015-ano-nao-terminar $>$

Este ano de 2015, já próximo do fim, está sendo de triste memória para o Direito Financeiro.

Começou mal, como destaquei em coluna publicada no início do ano, ${ }^{1}$ e está a poucos dias de terminar tão mal ou pior do que começou.

Faltando praticamente uma semana para o encerramento da sessão legislativa do Congresso Nacional, ainda não foram aprovados o Plano Plurianual 2016-2019 e o Orçamento da União para 2016, tudo indicando que não será novamente cumprido o prazo. Pior se verifica em relação à Lei de Diretrizes Orçamentárias LDO, cujo prazo expirou em julho, e está caminhando para quebrar o recorde do ano passado, em que acabou sendo aprovada no exercício seguinte.

E é pouco provável a aprovação do orçamento ou mesmo do Plano Plurianual, leis que geram debates intensos e tendem a não conseguir aprovação em épocas de difícil consenso, tal como a que se apresenta agora, em que os ânimos se acirraram e a votação do impeachment tende a ocupar a agenda política.

A menos que se concretize o alegado esforço concentrado anunciado para essa semana, ${ }^{2}$ corremos o risco de ficar sem as três leis que regulam o planejamento financeiro da administração pública federal, com reflexos no país inteiro, pois os entes subnacionais dependem fortemente das transferências intergovernamentais, tendo em vista nosso regime de federalismo cooperativo.

O direito financeiro precisa ser levado a sério, e 2015 começou mal, nesta edição, p. 183-188.

2 Congresso Nacional terá "super semana" de votaçôes. O Estado de S.Paulo, em 12 de dezembro de 2015. 
Uma mostra de descaso com o planejamento, já denunciado em coluna anterior, $^{3}$ que se perpetua e se agrava, com a falta de rumos do governo federal contaminando os demais entes da federação e impedindo que possam ser conduzidos de modo minimamente eficiente.

Da Lei do Plano Plurianual - PPA pouco se falou por ocasião da apresentação do seu projeto e raras são as referências a ela, às vésperas da data em que deveria ser aprovada ${ }^{4}$ o que evidencia não estar merecendo atenção. E é hoje não apenas o principal instrumento de planejamento da administração pública federal, mas de todo o país, ante a falta de leis que regulem o planejamento em âmbito nacional no médio e longo prazos. É alvissareira a notícia de que o projeto de PPA, ao menos, foi aprovado recentemente na Comissão Mista de Planos, Orçamentos Públicos e Fiscalização (CMO), e alinhado ao Plano Nacional de Educação - o mínimo que se espera de um governo que almeja ser o da "Pátria Educadora", embora os fatos, especialmente a constante troca de ministros da área, mitiguem a credibilidade dessa afirmação. ${ }^{5}$

Vê-se que o governo federal, ao que tudo indica, concentra todas as suas energias em tentar manter-se no poder, sem ter ideia do que fazer com ele. Se, como já mencionei anteriormente, governar sem um planejamento sério é como comandar um transatlântico no oceano sem mapa e instrumentos de navegação, e desconhecendo até mesmo o porto de destino, ${ }^{6}$ o que se vê atualmente é já existirem inúmeros furos no casco, sendo a preocupação tão somente de não afundar, pouco importando para onde ir.

Um dos mais lamentáveis atos praticados no final do ano passado, por incrível que pareça, volta a se repetir: a modificação da Lei de Diretrizes Orçamentárias às vésperas do final do exercício financeiro, para evitar que seja considerada violada. A LDO que fixou as diretrizes e metas para 2014 (Lei 12.919, de 24 de dezembro de 2013), em cumprimento à Lei de Responsabilidade Fiscal, estabeleceu a meta de superávit primário para o orçamento de 2014 em $\mathrm{R} \$ 116$ bilhões; em 15 de dezembro, poucos dias antes do fim do ano, a meta é substancialmente reduzida pela Lei 13.053.?

\section{Descaso com o planejamento deixa o país sem rumo, nesta edição, p. 139-144.}

4 Constituição, Ato das Disposições Constitucionais Transitórias, art. 35, $₫$ 2o, I: "o projeto do plano plurianual, para vigência até o final do primeiro exercício financeiro do mandato presidencial subsequente, será encaminhado até quatro meses antes do encerramento do primeiro exercício financeiro e devolvido para sanção até o encerramento da sessão legislativa”.

5 Comissão aprova PPA 2016-2019 alinhado ao Plano Nacional de Educação. Senado FederalPortal de Notícias, em 8 de dezembro de 2015.

6 Planejamento municipal precisa ser levado a sério, nesta edição, p. 135-138.

7 Acabar com a meta de superávit é irresponsabilidade fiscal, nesta edição, p. 395-400. 
Neste final de ano, os fatos reproduziram-se tal e qual! A LDO para 2015 (Lei 13.080, de 2 de janeiro de 2015) estabeleceu a meta de superávit primário em R \$ 66 bilhões, e, novamente constatada a inviabilidade de ser atingida, no apagar das luzes, é transformada em meta de resultado deficitário de R $\$ 49$ bilhões pela Lei 13.199, publicada em 3 de dezembro de 2015.

Em abril deste ano, em cumprimento ao prazo constitucional, ${ }^{8}$ foi apresentado o projeto de LDO para 2016, que deveria ter sido aprovado em julho, justamente para balizar a elaboração do orçamento, cujo projeto é apresentado no final de agosto. Nesta LDO, foi proposta a meta de superávit primário de R \$ 104 bilhões (orçamentos fiscal e da seguridade social); a LDO, no entanto, não foi aprovada ainda, o projeto de lei orçamentária já foi encaminhado, e não se cogita mais desses valores. E a todo momento surgem notícias de novos números, evidenciando descontrole e insegurança.?

Se os fatos ora relatados são de difícil compreensão para os leigos no tema, não se assustem, pois o que se vê é realmente o caos.

E o que se pode esperar, a partir de hoje, quanto à previsão das metas fiscais que cabe à LDO estabelecer, cumprindo o que determina a LRF? Qual o valor, credibilidade e segurança jurídica terá esse dispositivo de lei daqui para frente, quando foi flagrantemente afrontado e desconsiderado por dois anos seguidos? Pensando bem, talvez não seja algo de surpreender, partindo da Presidente que parece não compreender o significado do que é uma meta: "Não vamos colocar meta. Vamos deixar a meta aberta, mas quando atingirmos a meta, vamos dobrar a meta" (Dilma Rousseff, fazendo referência ao Pronatec - programa de qualificação profissional, em agosto).

A LDO representa hoje um importante instrumento de planejamento governamental e de gestão financeira, como já ressaltado anteriormente. ${ }^{10}$ É uma lei de validade temporal limitada, dada sua função precípua de estabelecer as diretrizes e metas para o exercício financeiro seguinte, orientando a elaboração da lei orçamentária anual, e atualmente regulando algumas questôes relacionadas à execução orçamentária.

8 Constituição, Ato das Disposições Constitucionais Transitórias, art. 35, $\$$ 2º II: “o projeto de lei de diretrizes orçamentárias será encaminhado até oito meses e meio antes do encerramento do exercício financeiro e devolvido para sanção até o encerramento do primeiro período da sessão legislativa".

9 Apesar das queixas de Levy, Dilma estuda redução da meta fiscal de 2016. O Estado de S.Paulo em 12 de dezembro de 2015.

10 LDO é instrumento eficiente para a administração pública, nesta edição, p. 151-154. 
E, mais recentemente, assumiu relevância a fixação das metas de resultado primário. Essa curta vigência já é um dos aspectos que tornam frágil sua eficácia. No entanto, essa fragilidade tem sido elevada ao seu grau máximo, fazendo a lei beirar a inutilidade, uma vez que as atitudes recentes têm desmoralizado completamente esse diploma normativo, ante os inusitados fatos ocorridos, levando a ineficácia dessa lei a um nível insustentável, o que é de se lamentar profundamente, pois seu cumprimento é essencial para uma gestão financeira responsável.

A desconsideração das metas tem sido uma verdadeira "pá de cal" nas esperanças de que se possa dar qualquer credibilidade a essa lei tão relevante, que hoje não mais transmite um mínimo de segurança jurídica e previsibilidade à ação governamental.

São demonstrações de que a irresponsabilidade fiscal ainda persiste, agora que se completam 15 anos da publicação da Lei de Responsabilidade Fiscal, ${ }^{11}$ e neste ano o retrocesso nessa área foi evidente.

Registre-se que alteração açodada das metas não se justifica pela alegação de terem ocorrido fatos imprevisíveis, que motivassem um repentino descompasso entre a arrecadação e as despesas, pois os estudos e relatórios periódicos do próprio governo já apuravam a baixa arrecadação e elevação das despesas obrigatórias. Mesmo assim, não foram tomadas as providências previstas na Lei de Responsabilidade Fiscal e na Lei de Diretrizes Orçamentárias vigente para manter o equilíbrio das contas públicas, sendo autorizados gastos em desconformidade à legislação, extrapolando as metas fixadas, em uma demonstração de irresponsabilidade na condução das finanças públicas, ${ }^{12}$ resultando no inevitável e previsível descontrole que agora se torna público, exigindo medidas drásticas de cortes abruptos nas despesas, sem critérios, estudos ou planejamento. ${ }^{13} \mathrm{Um}$ shutdown que em nada se parece com o americano, ocorrido em 2013, pois neste o problema não era a falta de dinheiro, mas a não aprovação tempestiva da lei orçamentária ante as divergências políticas do momento.

Acrescente-se ainda que os prazos de tramitação da LDO parecem ter virado "letra morta" da Constituição, que estabelece como data-limite para sua aprovação o final do primeiro período da sessão legislativa, que deveria se encerrar em julho,

11 Irresponsabilidade fiscal ainda persiste, 15 anos após a publicação da lei, nesta edição, p. 401-404.

12 Sem nova meta aprovada, Dilma ignora exigência de cortar R \$ 105 bi. Folha de S.Paulo, em 27 de novembro de 2105.

13 Governo confirma corte de R \$ 10 bi e paralisa a máquina federal. O Estado de S.Paulo, em 27 de novembro de 2015; Dilma cancela ida ao Japão e Vietnã e baixa decreto bloqueando gastos. Folha de S.Paulo, em 27 de novembro de 2015. 
mas não pode ser interrompido sem a aprovação do projeto de lei de diretrizes orçamentárias, na expressa disposição do art. $57, \$ 2^{\circ}$, da Constituição. E não parece ser o que tem ocorrido nos últimos anos, deixando entrever que o Congresso tem dado um "drible" nessa norma.

Somem-se a isso as "pedaladas" do Poder Executivo, que parecem não ter cessado, mesmo após as denúncias e apuraçoos, ${ }^{14}$ e teremos políticos capazes de formar uma seleção que jogue um futebol muito superior àquela que deu vexame na Copa do de $2014 \ldots$

O orçamento, com as indefinições na sua elaboração, sendo alterado do dia para a noite, em decisões tomadas em finais de semana, ${ }^{15}$ está se tornando pouco crível e confiável, justamente agora, que estava caminhando para deixar de ser uma "peça de ficção". Um retrocesso que diminui sua importância como instrumento de planejamento, gestão e controle da atividade financeira do Estado.

Além dessas dificuldades já descritas, que comprometem o equilíbrio das contas públicas e o controle do endividamento, ainda se perdem oportunidades de aprovar leis que poderiam promover avanços, como ocorreu recentemente com o projeto de resolução do Senado Federal que estabelecia limites globais para o montante da dívida consolidada da União. ${ }^{16}$

Em um ano marcado por "maquiagens contábeis", "pedaladas", alterações frequentes de metas e outras impropriedades que parecem não cessar, uma das poucas boas notícias é, na verdade, uma má notícia: o julgamento das contas de governo pelo Tribunal de Contas da União, que resultou no parecer pela rejeição, ante as múltiplas e graves irregularidades apuradas. ${ }^{17}$ Boa notícia por demonstrar a competência técnica e independência do TCU, que realizou trabalho detalhado, minucioso e bem fundamentado, e tomou decisão contrariando os interesses da mais alta autoridade do Poder Executivo. Má notícia porque não é nada bom saber que as finanças públicas estão sendo maltratadas e a legislação desrespeitada. Bom seria ter recebido a notícia de que as contas foram aprovadas por uma gestão financeira competente e responsável, que infelizmente não é o caso.

14 Como denunciou o Ministério Público de Contas junto ao TCU, e é um dos fundamentos o pedido de impeachment da Presidente.

15 Descaso com o planejamento deixa o país sem rumo, nesta edição, p. 139-144.

16 Projeto de Resolução do Senado 84, de 2007.

17 Julgamento do TCU que reprovou contas do governo entrou para a história do Direito Financeiro, nesta edição, p. 335-338. 
Tudo leva a crer que 2016 não será um bom ano. ${ }^{18} \mathrm{~A}$ inflação atinge os dois dígitos, ${ }^{19}$ renovam-se ameaças de rebaixamento pelas agências de risco ${ }^{20}$ e as más notícias não param de se avolumar.

É para se lamentar, pois 2015 deixou muito a desejar. Espera-se que, se a profecia se cumprir no que tange à economia e desenvolvimento do país, o mesmo não ocorra com o Direito Financeiro.

Se não há muito o que se esperar no aspecto econômico, pois as esperanças de melhorar são poucas, no aspecto jurídico isso só depende dos governantes, pois o dever de respeitar o ordenamento jurídico não é algo que se sujeite à conjuntura econômica ou social.

O Direito Financeiro tem mostrado sua importância e a necessidade de que suas normas sejam cumpridas. Questôes de Direito Financeiro sustentam a argumentação que pode levar um presidente a perder seu cargo por impeachment.

Muito do que está ocorrendo é consequência do desrespeito às normas vigentes, em especial as que tratam das finanças públicas, gerando descrença, desconfiança e insegurança jurídica.

A solução é simples: basta levar o Direito Financeiro a sério.

18 Pessimismo e desesperança devem pautar ano de 2016. Folha de S.Paulo, em 29 de novembro de 2015; Muito além dos 10 bilhões, editorial O Estado de S.Paulo, em 6 de dezembro de 2015.

19 Inflação volta aos dois dígitos pela primeira vez em 12 anos. O Estado de S.Paulo, em 10 de dezembro de 2015, p. B-3; Inflação supera dois dígitos pela $1^{\text {a }}$ vez desde 2003 . Folha de $S$. Paulo, em 10 de dezembro de 2015, p. A-18.

20 Moody's ameaça rebaixar o país após piora econômica e política. Folha de S.Paulo, em 10 de dezembro de 205, p. A-15; Agência Moody's ameaça tirar grau de investimento do Brasil em até 3 meses. O Estado de S.Paulo, em 10 de dezembro de 2015, p. B-1. 